\title{
Verification and Validation of Back-end Cycle Source Term Calculation of the Nodal Code RAST-K
}

\author{
Jaerim Jang, Bamidele Ebiwonjumi, Wonkyeong Kim, Jinsu Park and Deokjung Lee* \\ Department of Nuclear Engineering, Ulsan National Institute of Science and Technology, 50 \\ UNIST-gil, Ulsan, 44919, Republic of Korea
}

skansms0@unist.ac.kr, ebiwonjumi@unist.ac.kr, poryor@unist.ac.kr, jinsu@unist.ac.kr, *deokjung@unist.ac.kr

\begin{abstract}
Verification and validation $(\mathrm{V} \& \mathrm{~V})$ results of source term calculation capability implemented in the nodal diffusion code RAST-K are presented in this paper. An isotope inventory prediction method is presented in this work which is implemented with RAST-K and the lattice code STREAM. STREAM generates cross-section and provides number density information by history branch calculations. RAST-K supplies the power history and three history indexes (boron concentration, moderator temperature and fuel temperature). The main feature of the newly implemented spent nuclear fuel (SNF) characterization is the direct consideration of three-dimensional (3D) core simulation conditions by using operation history information. As a result of this, it could reduce the computation time. The implemented SNF analysis capability have two main functions. The first is to predict isotope inventory by Lagrange non-linear interpolation method, using power history correction factors. The second is to calculate the radiological response activity, decay heat, and neutron/gamma source strengths. The V\&V of these two functions are thus presented herein. The isotope inventory prediction is validated with measured data from ten SNF samples of Takahama-3 and six samples of Calvert Cliffs-1 pressurized water reactors (PWR). Eighteen decay heat measurements of Ringhals Unit 3 PWR fuel assemblies are then employed to validate the decay heat calculation results. In addition, STREAM is employed in a code-to-code comparison for verification. The fuel assemblies cover the burnup range $14.3-47.25 \mathrm{GWd} / \mathrm{tU}$, initial enrichment of $2.1-4.11{ }^{235} \mathrm{U}$ w/o and cooling time of 3.96 to 20.01 years. The comparison to STREAM shows the accuracy of the RAST-K SNF and prediction of the decay heat is within 4\%. Overall, this paper demonstrates that RAST-K SNF calculation can be applied to the back-end cycle source term analysis.
\end{abstract}

KEYWORDS: SNF, Radiation source terms, RAST-K, back-end cycle, isotope inventory

\section{INTRODUCTION}

The management of SNF is one of the most important issues in South Korea due to the saturation of the spent fuel pools (SFP). According to reports, 66 - 81\% storage capacity of the SFP is currently occupied and Kori nuclear power plants units 1 to 4 SFP will be fully saturated by 2024 [1]. To ensure the safety of management and transportation of the SNF, inventory calculation of SNF is important in order to predict the decay heat, radiological response activity, and neutron/gamma source strengths. Furthermore, this

\footnotetext{
*Corresponding author. Email: deokjung@unist.ac.kr
} 
calculation is required in the engineering design studies of radiation shielding and SNF casks. The calculation method presented in this work is implemented with the lattice code STREAM and nodal diffusion code RAST-K $[2,3]$. The main feature of the implemented method is that it can directly consider three-dimensional (3D) core simulation conditions by using history indexes of the operating conditions and, therefore, reduce the computation time. Previously, the calculation is performed in four steps: generation of cross-section by branch calculation in STREAM, 3D core simulation with RAST-K, STREAM 2D fuel assembly depletion with operation history information from RAST-K and lastly, source term calculation. The RAST-K source term calculation module can shorten the computation time by eliminating the third step. For a commercial PWR, 121 fuel assemblies and 24 axial nodes per assembly, i.e., reactor with 2,904 calculation nodes which is set for ensuring accuracy of the nodal calculation, RAST-K SNF module can reduce the computation time. About 30 days are required for STREAM to perform 2D fuel assembly depletion/source term calculation using power history information of each axial node from RAST-K, assuming the average depletion calculation time is 15 minutes per axial node. The RAST-K SNF module calculates the number densities by Lagrange non-linear interpolation method and power history correction factors. Power history correction factors are used to correct the effects of decay and fission products generated by different power levels.

Verification and validation (V\&V) results of RAST-K SNF module are presented in this report using 34 measured data of three different pressurized water reactors (PWR) (Takahama-3, Calvert Cliffs-1 and Ringhals-3). STREAM SNF module is employed to verify the RAST-K SNF calculation module. STREAM isotope inventory prediction and source term calculation capabilities have been validated against measurement data of SNF isotopic compositions and fuel assembly decay heat [4,5]. The 34 benchmarks presented in this paper cover $14.3-47.25 \mathrm{GWd} / \mathrm{tU}$ burnup, initial enrichment of $2.1-4.11{ }^{235} \mathrm{U}$ w/o and cooling time of $3.96-20.01$ years. The remainder of this paper is presented as follows. Section 2 describes the computational method of STREAM/RAST-K and the isotope inventory calculation method. Section 3 presents the V\&V of the isotope inventory and decay heat calculation results. Section 4 outlines the conclusion and future perspectives.

\section{DESCRIPTION OF COMPUTATIONAL METHOD}

This section describes the computational code system and deals with calculation method of predicting isotope inventory in the nodal diffusion code RAST-K. STREAM/RAST-K is used for 3D core simulation. STREAM generates the cross-section data and number density files for RAST-K nodal calculation. RAST$\mathrm{K}$ simulates the $3 \mathrm{D}$ core cases and generates three history indexes (boron concentration, fuel temperature and moderator temperature) for isotope inventory prediction.

\subsection{Management Code System}

The main workflow of the isotope inventory management code system is shown in Fig. 1. STREAM generates the cross-section (XS) data for 3D core simulation and number densities (about 1500 to 1640 isotopes) by history branch calculation and RAST-K calculates the three history indexes reflecting 3D reactor core simulation conditions. The prediction of isotope inventory is performed with history index and number density files by non-linear Lagrange interpolation in a way similar to the XS feedback module [3]. The difference is that a power correction factor is calculated to consider the different power levels. This is because the time steps used in STREAM 2D fuel assembly branch/depletion calculation is different from the time steps used in RAST-K 3D core depletion calculation. It is also important to note that 41 isotopes which are very sensitive to core power conditions are generated by RAST-K micro-depletion module [3]. STREAM (Steady state and Transient Reactor Analysis with Method of characteristics) is a lattice physics code and provides functionalized cross-section data of 2D assemblies [2]. The pointwise energy slowingdown method (PSM) is employed for resonance treatment [2]. During the branch calculation, the Chebyshev Rational Approximation Method (CRAM) and semi-predictor/corrector scheme are used for 
depletion calculations. RAST-K is a diffusion code based on the unified nodal method (UNM) and multigroup coarse mesh finite difference (CMFD) for achieving high performance [3].

In addition, Fig. 1 shows the difference between progress of RAST-K SNF module and of STREAM SNF module. STREAM SNF goes through one additional step to perform depletion calculation with 3D core operation history. STREAM SNF calculation is performed in 2D for every axial node in each fuel assembly (with reflective boundary condition). RAST-K SNF uses the 3D core operation history (with black radial boundary condition) for calculation and analysis.

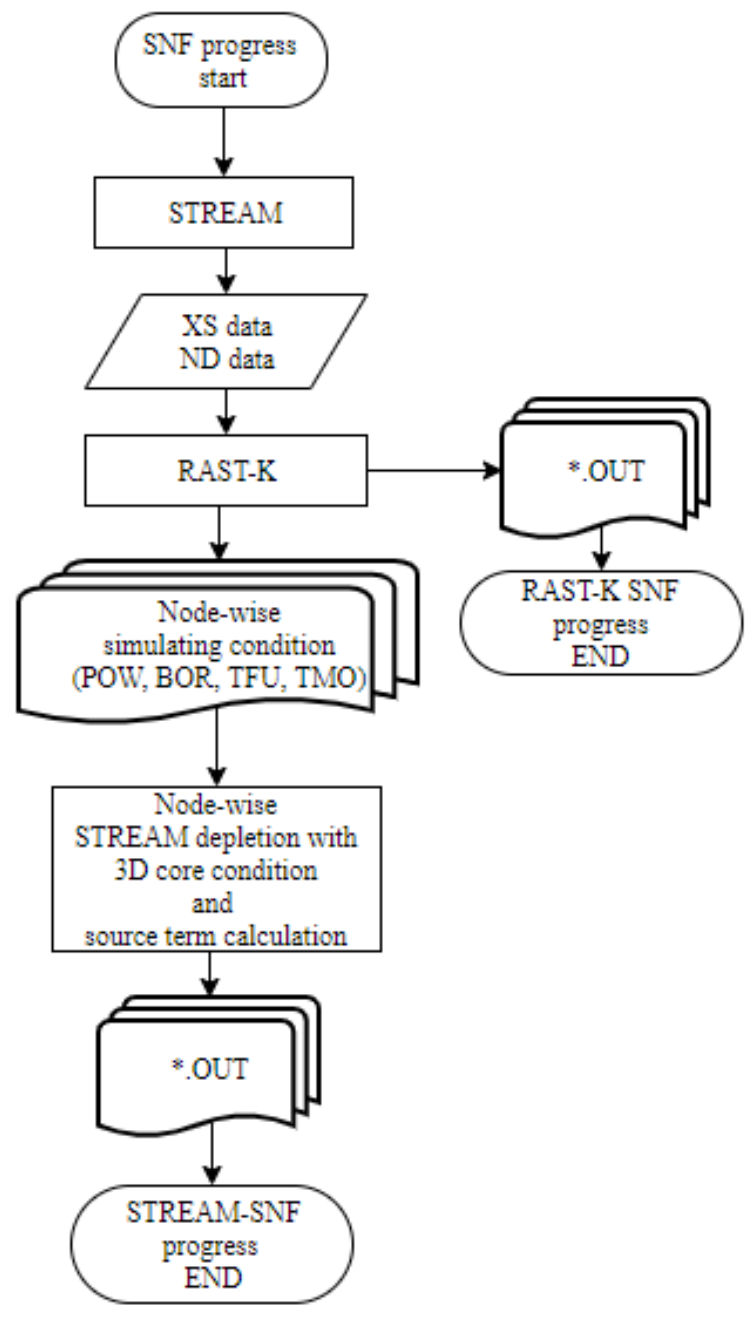

Figure 1. Flowchart of back-end management code system

\subsection{Calculation Method of Isotope Inventory}

The isotope inventory prediction method with non-linear Lagrange interpolation [6] is presented in Eq. (1),

$$
\begin{aligned}
N D_{\text {Lagrange }}= & N D_{B A S E}+\Delta N D_{T M O}+\Delta N D_{T F U}+\Delta N D_{B O R} \\
& =N D_{T M O}+N D_{T F U}+N D_{B O R}-2 * N D_{B A S E}
\end{aligned}
$$

where TMO is moderator temperature, TFU is fuel temperature and BOR is boron concentration. BASE is reference case of history branch calculation in STREAM. $N D_{\text {Lagrange, }} N D_{T M O}, N D_{T F O}$ and $N D_{B O R}$ are number 
densities calculated by Lagrange interpolation. History branch calculation is performed at four different $T M O$ states, two TFU stats and three $B O R$ states. During the Lagrange interpolation, the reference condition state is also considered. For instance, the number density is calculated with four different $T M O$ states and one reference condition by $4^{\text {th }}$ order Lagrange interpolation. $N D_{T F U}$ and $N D_{B O R}$ are calculated same way as

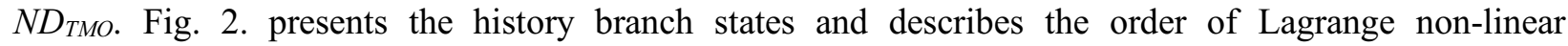
interpolation for three different cases, TMO, TFU and BOR.

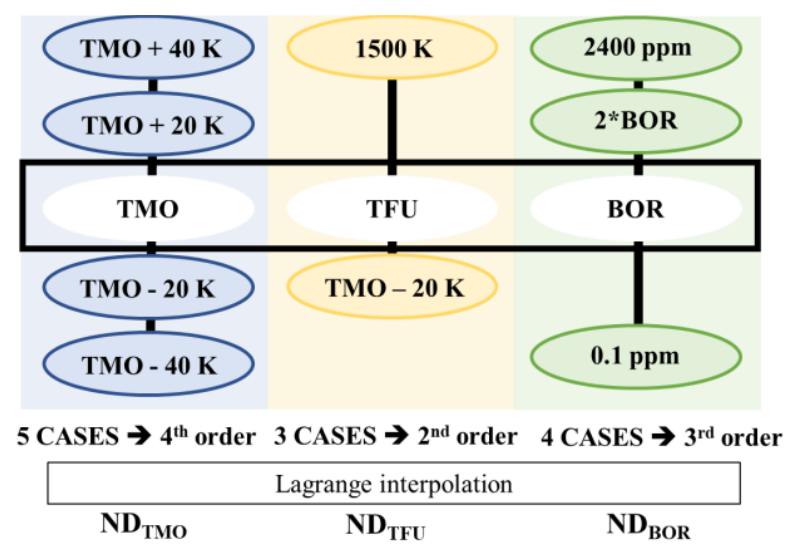

Figure 2. History branch states

Eq. (2) shows the power correction factor (PCF).

$$
P C F^{j, i}=\frac{N D_{2 D}^{j, i}}{N D_{3 D}^{j, i}}=\frac{N_{2 D}^{j, i} e^{-\lambda \Delta t_{2 D}}+\Delta N_{2 D}^{j, i}}{N_{3 D}^{j, i} e^{-\lambda \Delta t_{3 D}+\Delta N_{3 D}^{j, i}}}=\frac{C_{R A S T-K}^{j, i}}{C_{S T R E A M}^{j, i}}=\frac{C_{2 D}^{j, i} e^{-\lambda \Delta t_{2 D}}+\Delta C_{2 D}^{j, i}}{C_{3 D}^{j, i} e^{-\lambda \Delta t_{3 D}+\Delta C_{2 D}^{j, i}}}=\frac{C_{2 D}^{j, i} e^{-\lambda \Delta t_{2 D}+\mu_{2 D}^{j, i} F_{2 D}\left(1-e^{-\lambda \Delta t_{2 D}}\right)}}{C_{3 D}^{j, i} e^{-\lambda \Delta t_{3 D}+\mu_{3 D}^{j, i} F_{3 D}\left(1-e^{-\lambda \Delta t_{3 D}}\right)}}
$$

where $j$ is the isotope index, $i$ denotes the node index, $N D_{2 D}$ is the number density calculated by STREAM branch calculation, $N D_{3 D}$ is the number density generated by RAST-K, $\lambda$ is the decay constant, $\Delta t_{2 D}$ is the time interval between burnup steps used in STREAM, $\Delta t_{3 D}$ is the time interval generated by RAST-K 3D core follow simulation, $C$ is the concentration, $\mu$ is fission yield and $F$ is fission rate which is proportional to the nodal power density [7]. The term of $\Delta C_{2 D}^{j, i}=\mu_{2 D}^{j, i} F_{2 D}\left(1-e^{-\lambda \Delta t}\right)$ in equation (2) comes from Reference [7] and means the concentration generated by fission reaction. The PCF accounts for the difference decay effect caused by the different power levels and is applied to code as Eq. (3).

$$
N D_{\text {corrected }}=N D_{\text {Lagrange }} * P C F^{j, i}
$$

\section{V\&V Results}

34 benchmarks based on fuel assembly models are used in the V\&V for predicting isotope inventory and decay heat. For the isotope inventory prediction, the assemblies cover enrichment of $2.72-4.11{ }^{235} \mathrm{U}$ w/o, discharge burnup ranging from $14.3-47.25 \mathrm{GWd} / \mathrm{MTU}$, decay time of $3.960-6.504$ years and axial positions of $20.1-361.7 \mathrm{~cm}$ from bottom of FA. The assemblies used to validate the decay heat have enrichment of $2.1-3.1{ }^{235} \mathrm{U}$ w/o, burnup of $19.7-41.6 \mathrm{GWd} / \mathrm{MTU}$ and decay time of $15.94-20.01$ years.

\subsection{Isotope Inventory}

Sixteen benchmark cases are used for the $V \& V$ of the isotope inventory calculation, comprising of ten cases from Takahama-3 and six from Calvert Cliffs-1 PWRs. Takahama-3 is operated in Japan with $870 \mathrm{MWe}$ capacity and the isotopic assay of its SNF are measured by Japan Atomic Energy Research Institute (JAERI). 
Calvert Cliffs-1 is operated in the United States with capacity of 900 MWe and Pacific Northwest National Laboratory measured the SNF isotopic content [8]. The irradiation history information of the fuel samples (power, boron concentration, fuel temperature and moderator temperature) are described in the reference [8].

Two FA models of Calvert Cliffs- 1 are calculated for $V \& V$ and the positions of measured pins in the FA are shown in Fig. 3a. Moreover, the axial location of the fuel samples along the fuel rod active length are shown in Fig. $3 b$ and 3c. The average and standard deviation of C/E-1 (\%) for number density validation are presented in Table I. The scale of RAST-K errors is similar to STREAM-SNF.

Two measured fuel pins from Takahama-3 are also utilized for the isotope inventory V\&V and their positions in the FA and along the fuel rod are shown in Fig. 4a, 4b and 4c. The average and standard deviation of C/E-1 (\%) are described in Table II indicating similar scale of average errors. The simulation time of STREAM is about 15 min (900 seconds) per case and RAST-K is under 30 seconds. The time difference is caused by the additional step of depletion calculation shown in Fig. 1.

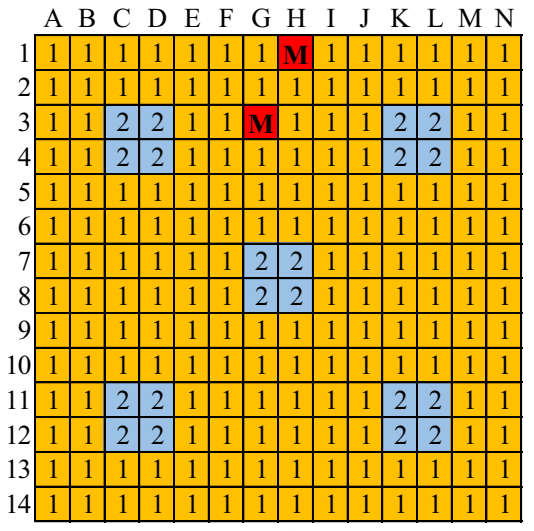

(a) Layout of D047 and D101 assemblies
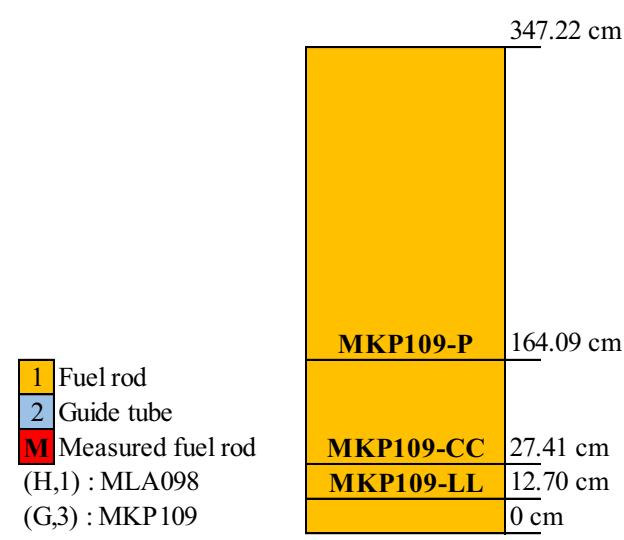

(b) Axial sample location in D047 asembly (c) Axial sample location in D101 asembly

$347.22 \mathrm{~cm}$

Figure 3. Radial and axial layout of Calvert Cliffs-1 FA

Table I: RMS error of MKP098 and MKP109 cases

\begin{tabular}{|c|c|c|c|c|c|c|c|c|c|}
\hline \multirow{3}{*}{$\begin{array}{c}\text { Sample ID } \\
\text { Code } \\
\text { Nuclide }\end{array}$} & \multirow{3}{*}{$\begin{array}{c}\sigma_{E}{ }^{* 4} \\
{[\%]}\end{array}$} & \multicolumn{4}{|c|}{ MKP098 } & \multicolumn{4}{|c|}{ MKP109 } \\
\hline & & \multicolumn{2}{|c|}{ STREAM-SNF } & \multicolumn{2}{|c|}{ RAST-K } & \multicolumn{2}{|c|}{ STREAM-SNF } & \multicolumn{2}{|c|}{ RAST-K } \\
\hline & & $\begin{array}{c}\overline{C^{* 1} / E^{* 2}-1} \\
{[\%]}\end{array}$ & $\begin{array}{l}\sigma^{* 3} \\
{[\%]}\end{array}$ & $\begin{array}{c}\overline{C / E-1} \\
{[\%]}\end{array}$ & $\begin{array}{c}\sigma \\
{[\%]}\end{array}$ & $\begin{array}{c}\bar{C} \overline{C / E-1} \\
{[\%]}\end{array}$ & $\begin{array}{c}\sigma \\
{[\%]}\end{array}$ & $\begin{array}{c}\overline{C / E-1} \\
{[\%]}\end{array}$ & $\begin{array}{c}\sigma \\
{[\%]}\end{array}$ \\
\hline${ }^{234} \mathrm{U}$ & 1.6 & -2 & 2.92 & -3 & 5.13 & -17 & 1.8 & -17 & 1.9 \\
\hline${ }^{235} \mathrm{U}$ & 1.6 & 11 & 6.33 & 11 & 6.20 & 9 & 5.0 & 9 & 4.8 \\
\hline${ }^{236} \mathrm{U}$ & 1.6 & -7 & 0.35 & -7 & 0.43 & -1 & 0.6 & -1 & 0.6 \\
\hline${ }^{238} \mathrm{U}$ & 1.6 & -1 & 0.30 & -1 & 0.30 & -1 & 0.2 & -1 & 0.2 \\
\hline${ }^{238} \mathrm{Pu}$ & 1.6 & -17 & 7.85 & -21 & 4.46 & -4 & 2.7 & -8 & 2.6 \\
\hline${ }^{239} \mathrm{Pu}$ & 1.6 & 14 & 5.92 & 14 & 4.75 & 17 & 3.6 & 17 & 3.1 \\
\hline${ }^{240} \mathrm{Pu}$ & 1.6 & 1 & 1.21 & 1 & 0.81 & 4 & 0.8 & 3 & 0.5 \\
\hline${ }^{242} \mathrm{Pu}$ & 1.6 & -9 & 2.58 & -9 & 2.40 & -2 & 2.3 & -1 & 2.2 \\
\hline${ }^{237} \mathrm{~Np}$ & 1.9 & -3 & 6.59 & -4 & 5.65 & 11 & 5.1 & 10 & 5.0 \\
\hline${ }^{79} \mathrm{Se}$ & $-{ }^{* 5}$ & 25 & 0.62 & 26 & 0.37 & 36 & 4.0 & 37 & 3.9 \\
\hline${ }^{90} \mathrm{Sr}$ & 5.7 & 10 & 6.67 & 16 & 0.85 & 14 & 0.4 & 18 & 0.7 \\
\hline${ }^{99} \mathrm{Tc}$ & 3.5 & -1 & 1.14 & -1 & 1.26 & 6 & 3.0 & 5 & 3.1 \\
\hline${ }^{135} \mathrm{Cs}$ & 14.0 & 16 & 2.46 & -24 & 12.03 & 11 & 1.2 & -21 & 10.6 \\
\hline${ }^{137} \mathrm{Cs}$ & 3.5 & 8 & 5.76 & 14 & 1.12 & 11 & 1.4 & 15 & 1.4 \\
\hline
\end{tabular}

${ }^{* 1}$ calculated isotope inventory, ${ }^{* 2}$ measured data.

$\overline{C / E-1}=\frac{1}{N} \sum_{i=1}^{N}(C / E-1)_{i}$ 
*3 $\sigma=\sqrt{\frac{\sum_{i=1}^{N}\left(\left(\frac{C}{E}-1\right)-\left(\overline{\frac{C}{E}-1}\right)\right)^{2}}{N-1}}$, where $N$ is the number of cases.

${ }^{* 4} \sigma_{E}$ is shown in [8], ${ }^{* 5}$ means experimental standard deviation doesn't mention in reference [8].

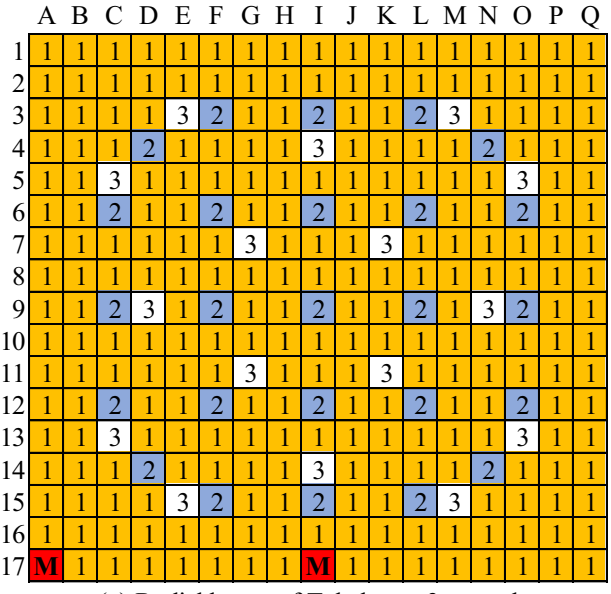

(a) Radial layout of Takahama-3 assemby

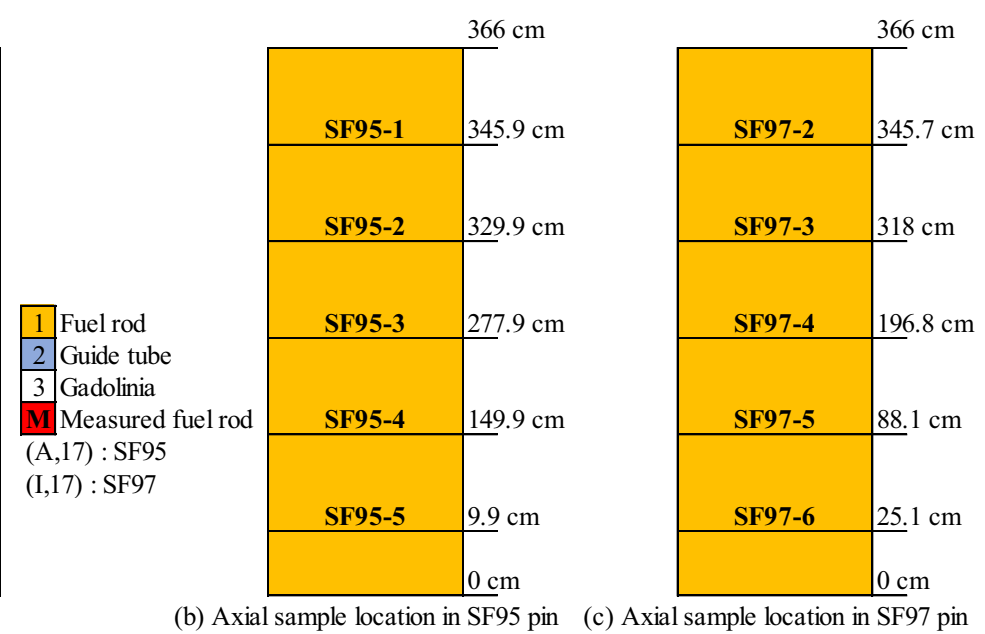

(b) Axial sample location in SF95 pin (c) Axial sample location in SF97 pin

Figure 4. Radial and axial layout of Takahama-3 FA

Table II: RMS error of SF95 pin and SF97 pin

\begin{tabular}{|c|c|c|c|c|c|c|c|c|c|}
\hline \multirow{3}{*}{$\begin{array}{c}\text { Sample ID } \\
\text { Code } \\
\text { Nuclide }\end{array}$} & \multirow{3}{*}{$\begin{array}{c}\sigma_{E}{ }^{* 4} \\
{[\%]}\end{array}$} & \multicolumn{4}{|c|}{ SF95 } & \multicolumn{4}{|c|}{ SF97 } \\
\hline & & \multicolumn{2}{|c|}{ STREAM-SNF } & \multicolumn{2}{|c|}{ RAST-K } & \multicolumn{2}{|c|}{ STREAM-SNF } & \multicolumn{2}{|c|}{ RAST-K } \\
\hline & & $\begin{array}{c}C^{* 1} / E^{* 2}-1 \\
{[\%]}\end{array}$ & $\begin{array}{l}\sigma^{* 3} \\
{[\%]}\end{array}$ & $\begin{array}{c}\overline{C / E-1} \\
{[\%]}\end{array}$ & $\begin{array}{c}\sigma \\
{[\%]}\end{array}$ & $\begin{array}{c}\overline{C / E-1} \\
{[\%]}\end{array}$ & $\begin{array}{c}\sigma \\
{[\%]}\end{array}$ & $\begin{array}{c}\overline{C / E-1} \\
{[\%]}\end{array}$ & $\begin{array}{c}\sigma \\
{[\%]}\end{array}$ \\
\hline${ }^{234} \mathrm{U}$ & 1.0 & 12 & 14.18 & 12 & 14.38 & 9 & 1.6 & 9 & 1.6 \\
\hline${ }^{235} \mathrm{U}$ & 0.1 & 2 & 0.55 & 1 & 0.98 & 3 & 2.7 & 2 & 2.8 \\
\hline${ }^{236} \mathrm{U}$ & 2.0 & -2 & 0.88 & -2 & 0.94 & -1 & 0.4 & -1 & 0.6 \\
\hline${ }^{238} \mathrm{U}$ & 0.1 & 0 & 0.02 & 0 & 0.04 & 0 & 0.1 & 0 & 0.0 \\
\hline${ }^{238} \mathrm{Pu}$ & 0.5 & -12 & 3.42 & -12 & 5.16 & -17 & 3.1 & -9 & 12.4 \\
\hline${ }^{239} \mathrm{Pu}$ & 0.3 & 2 & 2.01 & 0 & 3.25 & 1 & 3.2 & 1 & 3.3 \\
\hline${ }^{240} \mathrm{Pu}$ & 0.3 & 2 & 1.64 & 1 & 2.32 & 6 & 1.7 & 5 & 1.8 \\
\hline${ }^{241} \mathrm{Pu}$ & 0.3 & -3 & 2.69 & -5 & 3.36 & -3 & 3.7 & -2 & 4.6 \\
\hline${ }^{242} \mathrm{Pu}$ & 0.3 & -5 & 2.68 & -6 & 2.19 & -6 & 0.8 & -4 & 4.3 \\
\hline${ }^{241} \mathrm{Am}$ & 2.0 & -1 & 10.79 & 2 & 11.98 & 13 & 7.6 & 20 & 7.5 \\
\hline${ }^{243} \mathrm{Am}$ & 5.0 & 3 & 1.98 & 1 & 4.64 & -1 & 3.9 & 0 & 3.9 \\
\hline${ }^{242} \mathrm{Cm}$ & 10.0 & -36 & 8.92 & -30 & 10.38 & 5 & 9.3 & 14 & 9.5 \\
\hline${ }^{243} \mathrm{Cm}$ & 2.0 & -44 & 3.55 & -36 & 4.96 & -36 & 4.4 & -18 & 23.4 \\
\hline${ }^{244} \mathrm{Cm}$ & 2.0 & -10 & 5.50 & -12 & 8.43 & -14 & 5.8 & -8 & 11.4 \\
\hline${ }^{246} \mathrm{Cm}$ & 5.0 & 16 & 29.70 & -13 & 38.95 & -15 & 8.3 & -10 & 12.9 \\
\hline${ }^{137} \mathrm{Cs}$ & 3.0 & -4 & 0.85 & -4 & 0.52 & -6 & 5.1 & -3 & 2.2 \\
\hline${ }^{134} \mathrm{Cs}$ & 3.0 & 3 & 10.12 & -8 & 2.35 & -4 & 5.6 & -7 & 5.2 \\
\hline
\end{tabular}

$* 1,2,3,4$ See footnote of Table I. 


\subsection{Decay Heat}

Fuel assemblies from Ringhals-3 PWR operated in Sweden are used for the decay heat V\&V and the operation history is described in the reference [9]. The assembly design is 17 by 17 and their layouts are shown in Fig. 5. Fig. 6 shows the relative error of the assembly decay heat calculations compared to 18 measurements. The notation of $* 1$ to $* 5$ in $5 \mathrm{~A} 3$ indicates the different samples. The errors of STREAM are within $3 \sigma$ and those of RAST-K are within $2 \sigma$. The sigma values correspond to the measurement uncertainty calculated by Eq. (4)

$$
\sigma[\%]=((E[W] \pm \text { measurement uncertainty }[W]) / E[W]-1) * 100[\%]
$$

where, $E$ is the measured decay heat. Details of the measurement uncertainty can be found in $[4,9]$. Fig. 7 shows the decay heat results as a function of decay time and burnup and there is no observable trend. The relative errors of the 18 cases considered are within $\pm 4 \%$.

\begin{tabular}{|l|l|l|l|l|l|l|l|l|}
\hline 2 & 1 & 1 & 3 & 1 & 1 & 3 & 1 & 1 \\
\hline 1 & 1 & 1 & 1 & 1 & 1 & 1 & 1 & 1 \\
\hline 1 & 1 & 1 & 1 & 1 & 1 & 1 & 1 & 1 \\
\hline 3 & 1 & 1 & 3 & 1 & 1 & 3 & 1 & 1 \\
\hline 1 & 1 & 1 & 1 & 1 & 1 & 1 & 1 & 1 \\
\hline 1 & 1 & 1 & 1 & 1 & 3 & 1 & 1 & 1 \\
\hline 3 & 1 & 1 & 3 & 1 & 1 & 1 & 1 & 1 \\
\hline 1 & 1 & 1 & 1 & 1 & 1 & 1 & 1 & 1 \\
\hline 1 & 1 & 1 & 1 & 1 & 1 & 1 & 1 & 1 \\
\hline
\end{tabular}

(a) FA01

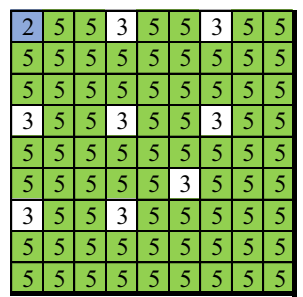

(b) FA02

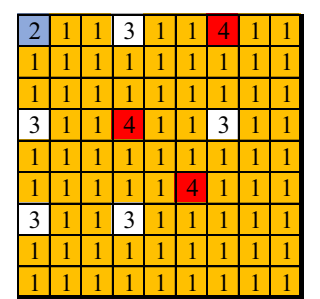

(c) FA03

Figure 5. one-fourth fuel assembly layout of Swedish PWR

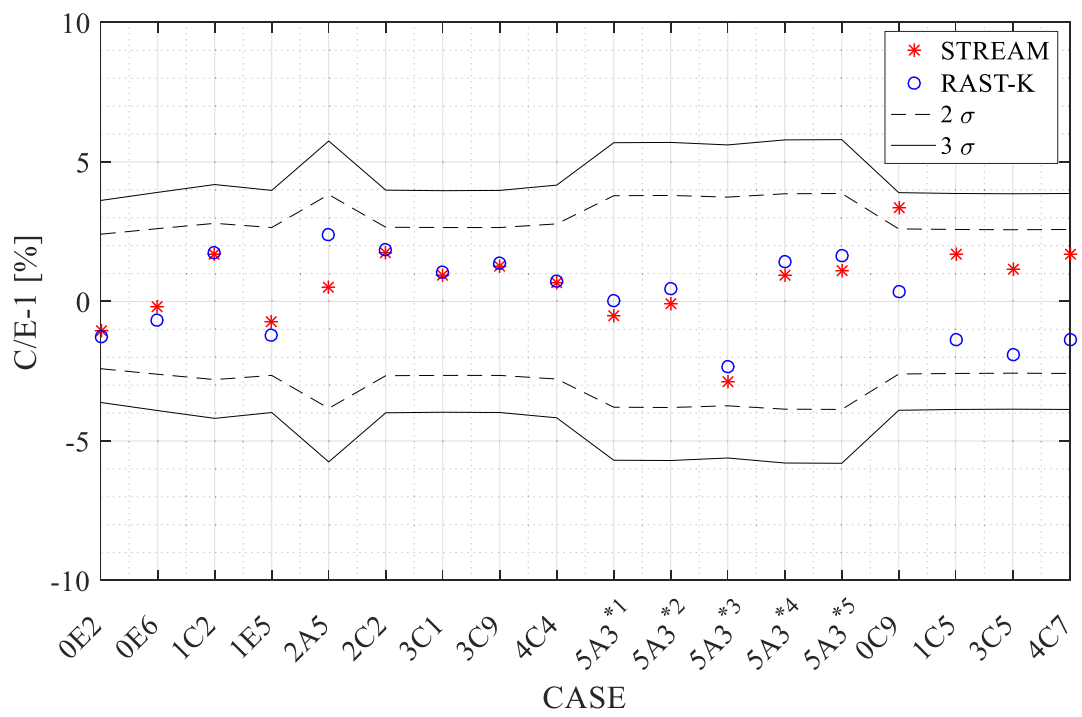

Figure 6. Relative error of decay heat 

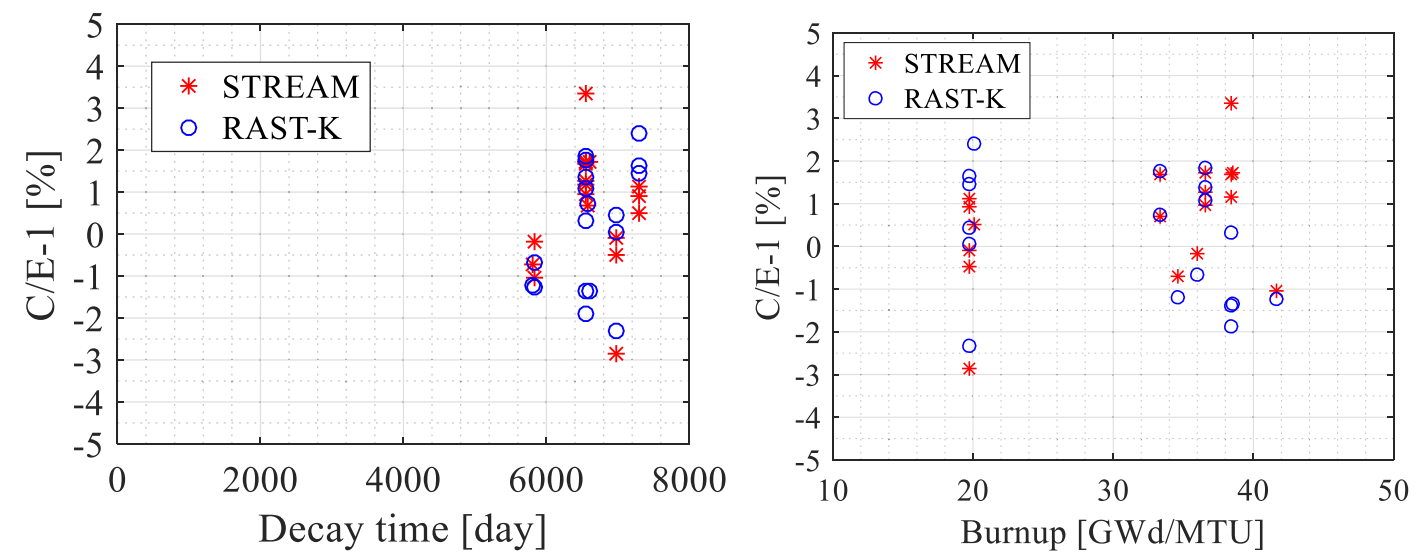

Figure 7. Decay heat results as function of decay time and burnup

\section{CONCLUSIONS}

An SNF module is developed and implemented in the nodal code RAST-K and the V\&V is presented in this work. The V\&V covers isotope inventory and decay heat calculations of realistic benchmark cases employing detailed irradiation history information. Measurement data of SNF isotopic assay and assembly decay heat have been employed for the V\&V. A validated code STREAM-SNF is employed for verification. The relative differences of isotope inventory prediction of RAST-K have similar scale with STREAM-SNF. RAST-K decay heat results are within 2-sigma of measurement uncertainty for the cases analyzed and the relative errors are within $\pm 4 \%$. Overall, this paper demonstrates that RAST-K SNF calculation can be applied to the back-end cycle source term analysis. In the future, other types of assemblies/Westinghouse 2-Loop (WH2L) PWR assemblies, a type of South Korean PWR, will be tested for V\&V. In addition, to reduce the memory of number density file, binary format file will be introduced.

\section{REFERENCES}

1. Status of spent fuel storage for the first quarter of 2019, 2019e [Online]. (Available from: http://www.khnp.co.kr/board/BRD_000179/boardView.do?pageIndex=1\&boardSeq=70138\&mnCd= FN051304\&schPageUnit=10\&searchCondition=0\&searchKeyword= ) Accessed on April 2019.

2. S, Choi., C, Lee., D, Lee., Resonance Treatment using Pin-Based Pointwise Energy Slowing-Down Method, J. Comput. Phys., 330: 134-155. (2017)

3. J, Choe., S, Choi., P, Zhang., J, Park., W, Kim., HC, Shin., HS, Lee., J, Jung and D, Lee., Verification and Validation of STREAM/RAST-K for PWR Analysis, Nucl. Eng. Tech., 51(2): 356-368 (2019)

4. B, Ebiwonjumi., S, Choi., M, Lemaire and D, Lee., Verification and Validation of Radiation Source Term Capabilities in STREAM," Ann. Nucl. Energy, 124: 80-87 (2019)

5. B, Ebiwonjumi., S, Choi., M, Lemaire., D, Lee and HC, Shin., Validation of Lattice Physics Code STREAM for Predicting Pressurized Water Reactor Spent Nuclear Fuel Isotopic Inventory," Ann. Nucl. Energy, 120: 431-449 (2018)

6. A, Quarteroni., R, Sacco. and F, Saleri., Numerical Mathematics, 2007

7. Sigurd Børresen, Spent Nuclear Fuel Analyses based on In-Core Fuel Management Calculations, PHYSOR, Chicago, Illinois, April 25-29, 2004

8. G. Radulescu, I. C. Gauld, G. Ilas, SCALE 5.1 Predictions of PWR Spent Nuclear Fuel Isotopic Compositions, March (2010)

9. Svensk Kärnbränslehantering $\mathrm{AB}$, Measurements of decay heat in spent nuclear fuel at the Swedish interim storage facility, Clab, December (2006). 